\title{
Beyond Inherent Routing Metrics: A simulated comparison of Routing Information Protocol and Enhanced Interior Gateway Routing Protocol.
}

\author{
Danquah P. (PhD), Lartey J.D. \& Kani J.A. \\ Department of Information Technology \\ Heritage Christian University College \\ Accra, Ghana \\ E-mails: Pdx017a@hcuc.edu.gh, Jdl015a@hcuc.edu.gh, jak017a@hcuc.edu.gh
}

\begin{abstract}
This paper empirically compared the two routing protocols Routing Information Protocol (RIP) and Enhanced Interior Gateway Routing Protocol (EIGRP). A simulated environment was developed with a network setup to test and compare overall throughput of data transmission output in the contextual implementation of either routing protocols. The results of the experiment showed that RIP provides faster transmission and response times as compared to EIGRP implementation under the simulated environment in the event of all conditions are equal. This paper used a simulated environment to compare the routing protocols' performance in an attempt to go assess the specific protocols beyond their inherent features.
\end{abstract}

Keywords: Routing Protocols, Protocol performance, RIP, EIGRP, Comparing Routing Protocols

Aims Research Journal Reference Format:

Danquah P., Lartey J.D. \& Kani J.A. (2018): Beyond Inherent Routing Metrics: A simulated comparison of Routing Information Protocol and Enhanced Interior Gateway Routing Protocol. Advances in Multidisciplinary \& Scientific Research Journal. Vol. 4. No.2, Pp 35-46

\section{INTRODUCTION.}

Computer networks that have routers may have routing done statically or dynamically in its implementation. Dynamic routing protocols may be implemented to reduce administrative work and also make room for scalability or easy growth of the network. Routing dynamically requires the implementation and configuration of routing protocols, a routing protocol is a language or set of rules by which routers share information about the reachability and status of networks. The criteria for exchanging routing information typically includes procedure to select the best path based on the destination's reachability information in a route table. The procedure leverages on routing metrics that is determined through specific routing algorithms of the specific routing protocol in use. The routing metrics is used to determine a ranking of paths to a remote destination from the most preferred to least preferred. The metrics range from hop counts, costs, routing convergence, scalability and other factors. Routing protocols may share information via varying approaches depending on its design, information may be shared first among its immediate neighbors, and then subsequently throughout the network. Routers ultimately obtain knowledge of the topology of the network.

\subsection{Objective}

This paper sets out to compare routing protocols based on results obtained from tests carried beyond the inherent metrics of the routing protocols. Specifically, network round trip times and time to live are used to compare the protocols on the basis of message round trip and time to live for packets transmitted.

\section{LITERATURE REVIEW}

Types of Routing Protocols: "Routing protocols are classified into distance vector and link state. Distance vector routing protocol is based on Bellman - Ford algorithm and Ford - Fulkerson algorithm to calculate paths" (Wang, Chang \& Cheng, 2009). A distance vector routing protocol uses a distance calculation and a vector direction of next hop router as reported by neighboring routers to choose the best path. It requires that a router informs its neighbors of topology changes periodically. "Link state routing protocols build a complete topology of the entire network are and then calculating the best path from this topology of all the interconnected networks" (Seeger \& Khanna, 1986). Generally, link state routing protocols require more processing power and memory due to its tendercy to have a complete picture of the network. Classful and Classless Routing Protocols: Classful routing protocols are routing protocols that do not transmit subnet mask information within the routing updates, they also operate in such a way that that every interface and host on the network must essentially use the same subnet mask in addressing. 
The classful routing protocols therefore have the tendency to be wasteful with more address spaces and also sending out periodic routing updates to all active interfaces of each router thereby causing congestion on the slower Wide Area Network links (Fuller \& Li, 2006). Classless routing protocols on the other hand include subnet mask information when transmitting routing updates to neighboring routers' routing tables. As classless routing protocols' updates are exchanged, it allows using the networks with the different length of subnet masks thus supporting Classless Inter-Domain Routing (CIDR) and Variable Length Subnet Mask (VLSM). Classless routing protocols exchange the entire routing table with the neighbor routers only at the very first time and routing updates are sent only when changes occur in the network topology (Doyle \& Carroll , 2005). This significantly reduces bandwidth consumption.

\subsection{Static and Dynamic Routing}

Routing may be done statically or dynamically, Static routing is the process of manually making routing entries into a router's routing table, in static routing, all the changes in the layout of the logical network must be manually done by the system administrator. Dynamic routing on the other leverages on the routing protocols to automatically gathers routing paths from other connected routers to determine the best path even if or when there is a real time logical network layout change.

"Dynamic routing protocols are also further categorized into Interior Gateway Protocols (IGP) distance vector, IGP linkstate and Exterior Gateway Protocols (EGP)" (Lammle, 2007). Typical examples are Routing Information Protocol, Open Shortest Path First and Border Gateway Protocol respectively.

\subsection{The Routing Protocols in Context}

Routing Information Protocol (RIP): This routing protocols is a distance-vector routing protocol which employs the concept of hop count as its routing metric. RIP makes use of limits on number of hops allowed to prevent possible routing loops between source to destination. RIP inherently allows a maximum of 15 hops from source to destination, this invariably limits the size of networks that RIP can support. "RIP implements the split horizon, route poisoning and holddown mechanisms to prevent incorrect routing information from being propagated" (Lammle, 2007). Routers running RIP by default broadcast updates with their routing table every 30 seconds, RIP has not been successful in scaling as networks have grown due to bursts in data transmission experienced every 30 seconds even if the routers had been initialized at random times (Balchunas, 2014). It is however relatively easy to configure RIP because its configuration parameters are not many in number compared with other routing protocols. RIP is classful and as such does assume the default subnet mask during broadcast updates of the routing tables.

RIP version 2(RIPv2) was introduced as a result of challenges in implementation of RIP, RIP version 2 was developed with the ability to transmit subnet information during the exchange of routing updates for routing tables, thereby supporting Classless Inter-Domain Routing (CIDR). To make sure that it was backward compatible with RIP, the hop count limit of 15 was maintained. "RIPv2 has facilities to fully interoperate with the earlier specification" (Atkinson \& Fanto, 2007). To avoid a situation where unnecessary load is put on hosts that do not participate in routing, RIPv2 multicasts the entire routing table to all adjacent routers at the address 224.0.0.9 unlike RIPv1 which uses broadcast.

"Enhanced Interior Gateway Routing Protocol (EIGRP) is an advanced distance-vector routing protocol that is used on a computer network for automating routing decisions and configuration" (Lammle, 2007). The protocol was originally designed by Cisco Systems, it was also originally a proprietary routing protocol which was used to share routes with other routers within the same autonomous system. It was designed to only share incremental routing updates thereby reducing the workload on the routers and the amount of data that needs to be transmitted.

EIGRP operates in such a way that almost all routers contain a routing table which has embedded rules by which traffic is forwarded in a network. Technically, it leverages on the tables called neighbour, topology and routing table to store information about the network and how to reach destinations. "When a router running EIGRP is connected to another router also running EIGRP, information is exchanged between the two routers and a relationship is formed known as an adjacency. The entire routing table is exchanged between both routers at this time. After this has occurred, only differential changes are sent" (Pepelnjak, 2000). EIGRP is often considered a hybrid protocol because it is also sends link state updates when link states change. EIGRP is considered relatively optimal as compared to RIP in large networks because it updates only when a topology changes but not periodically unlike old Distance-Vector protocols such as RIP. The EIGRP metric is based on its bandwidth, delay, reliability, load and Maximum Transmission Unit (MTU). 


\subsection{Related Research Work}

(Scepanovic \& Vukotic, 2013) compared RIP and EIGRP in their study and produced the figure 2 as the output of convergence time for the two routing protocols. This was evidently based on inherent functionalities of the routing protocols.

Table 1: Time of Convergence in Network

\begin{tabular}{|c|c|c|}
\hline Number of routers & RIP & EIGRP \\
\hline 2 & 2.027875 & 1.084125 \\
\hline 3 & 4.058250 & 5.113500 \\
\hline 4 & 6.091125 & 5.142875 \\
\hline 5 & 8.126500 & 5.172250 \\
\hline 6 & 10.164380 & 5.201625 \\
\hline 7 & 12.204750 & 5.231000 \\
\hline 8 & 14.247630 & 5.260375 \\
\hline 9 & 16.313000 & 5.314250 \\
\hline 10 & 18.340880 & 5.319125 \\
\hline 11 & 20.391250 & 5.348500 \\
\hline 12 & 22.444130 & 5.377875 \\
\hline 13 & 24.499500 & 5.407250 \\
\hline 14 & 26.557380 & 5.436625 \\
\hline 15 & 28.617750 & 5.466000 \\
\hline 16 & 30.680630 & 5.495375 \\
\hline
\end{tabular}

The time of convergence in networks organized as bus topology obtained by the si: Source: Scepanovic S. And Vukotic I. (2013)

In Scepanovic et al. (2013)'s same research work, the simulated topologies displayed in figure 1 were used to test the message sending times when bandwidth of RIP path is 56Kbps and also when bandwidth of EIGRP path is $10 \mathrm{Mbps}$. This output is shown in figure 4 and message sending times when bandwidth of RIP path is 10Mbps and bandwidth of EIGRP path is $100 \mathrm{Mbps}$ is shown in figure 5 .

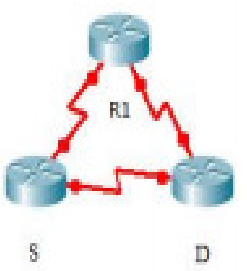

Topology A

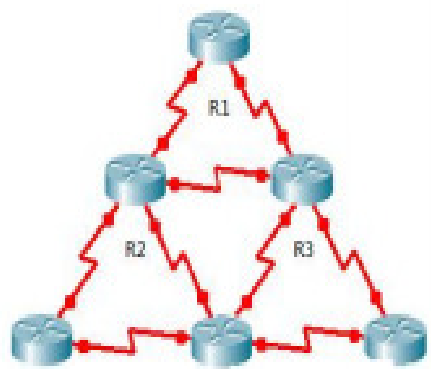

P

D

Topology B

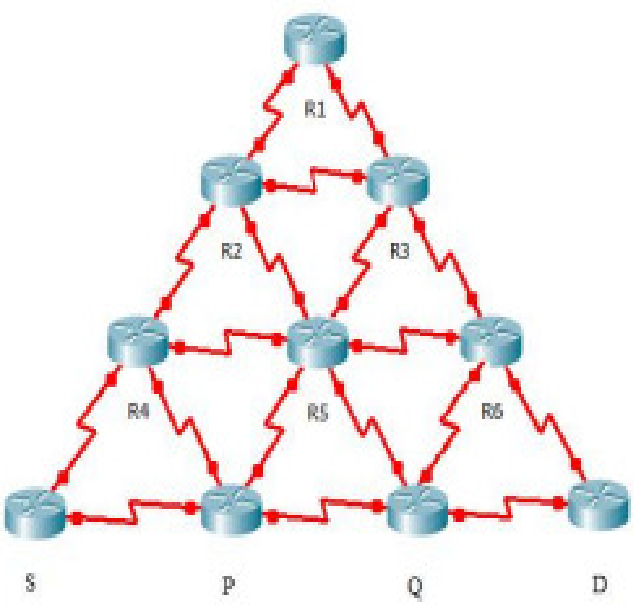

Topology C

Figure 1: Source is Scepanovic S. And Vukotic I. (2013) 
Table 2: Results when 100 packages are sent between the source and the destination

\begin{tabular}{|c|c|c|c|c|}
\hline & \multicolumn{2}{|c|}{ RIP } & \multicolumn{2}{c|}{ EIGRP } \\
\hline$v_{f} / v_{p}$ & $100 \mathrm{MB} / 1 \mathrm{MB}$ & $1 \mathrm{MB} / 1 \mathrm{bit}$ & $100 \mathrm{~KB} / 1 \mathrm{MB}$ & $1 \mathrm{MB} / 1 \mathrm{bit}$ \\
\hline Topology A & 14979.95714 & 25315.6765 & 82.74285772 & 138.5027406 \\
\hline Topology B & 15129.75871 & 25315.68151 & 84.38529056 & 138.5067736 \\
\hline Topology C & 15279.56029 & 25315.68653 & 86.0277234 & 138.5108066 \\
\hline
\end{tabular}

Source is Scepanovic \& Vukotic, 2013

Table 3: Results when 8388608 packages are sent between the source and the destination

\begin{tabular}{|c|c|c|c|c|}
\hline & \multicolumn{2}{|c|}{ RIP } & \multicolumn{2}{c|}{ EIGRP } \\
\hline$v_{f} / v_{p}$ & $100 \mathrm{MB} / 1 \mathrm{MB}$ & $1 \mathrm{MB} / 1 \mathrm{bit}$ & $100 \mathrm{MB} / 1 \mathrm{~KB}$ & $1 \mathrm{MB} / 1 \mathrm{bit}$ \\
\hline Topology A & 81.9216413 & 138.5007241 & 8.27608639 & 13.90240572 \\
\hline Topology B & 82.74285772 & 138.5027406 & 8.443929698 & 13.90640905 \\
\hline Topology C & 83.56407414 & 138.5047571 & 8.611773006 & 13.91041238 \\
\hline
\end{tabular}

Source is Scepanovic \& Vukotic, 2013

Results in tables 2 and 3 depended on "the number of packages which had to be sent and two situations were considered, when 100 packages are sent between the source and the destination and when 8388608 packages are sent between the source and the destination" (Scepanovic et al, 2013).

Deng \& Sun (2014) in their study instructively concluded that EIGRP is the best choice for both large and small networks since it has the fastest convergence and EIGRP uses the bandwidth efficiently.

\section{METHODOLOGY}

Simulated methodologies are typically classified from three perspectives in literature. One answer is that all talk of "simulation" and "numerical experiments" is purely hyperbolic or metaphorical-simulation is nothing more and nothing less than using brute-force computational means to solve analytically intractable equations. A second view, in which the terms "simulation" and "numerical experiment" are taken quite literally, a simulation is a stand-in, or mimic, of a real-world system, and can therefore be experimented on just like any other experimental target. The third is the view that simulation is a brand new "third mode" of science, neither experimental nor theoretical. (Winsberg, 2003). This research specifically uses a simulator called Packet Tracer developed by cisco systems to technically generate and compare the output of routing protocols as they converge and route data. The comparison is done using the round trip time and time to live.

Round-trip time (RTT) is defined as the length of time taken for a signals to be sent plus the length of time it takes for an acknowledgement of the signal to be received. The time delay in this context also includes the propagation times for the paths between the two communication endpoints (Comer, 2000). Time to live (TTL) on the other hand is a mechanism that limits the lifespan or lifetime of data in a computer or network. TTL is typically deployed either as a counter or timestamp in the data. In some instances, it may be attached to the data. The objective of implementing TTL is the effectively ensure that data is discarded or revalidated when the prescribed event count or the prescribed timespan has elapsed.

The simulator is used to setup a network consisting of a set of computers on two separate local area networks interconnected via two optional paths consisting of four routers. The paths are segmented into paths one and two with bandwidths of $64 \mathrm{Kbps}$ and $1024000 \mathrm{Kbps}$ respectively. The configuration of RIP and EIGRP are effected on all routers separately and connectivity between the two networks is tested. Specifically, connectivity is tested between PC2 and PC0, thus, 20.0.0.1/8 and 10.0.0.1/8. This test is done via paths one and two separately to record round trip times and time to live values for purposes of comparison. The ultimate comparison of the feedback depicts the efficiency of the specific routing protocols comparatively, the model of routers used was cisco 2900 at all routing points. 


\section{Advances In Multidisciplinary}

Ains \& Scientific Research

A visual representation of the network topology is displayed in figure 2 below.

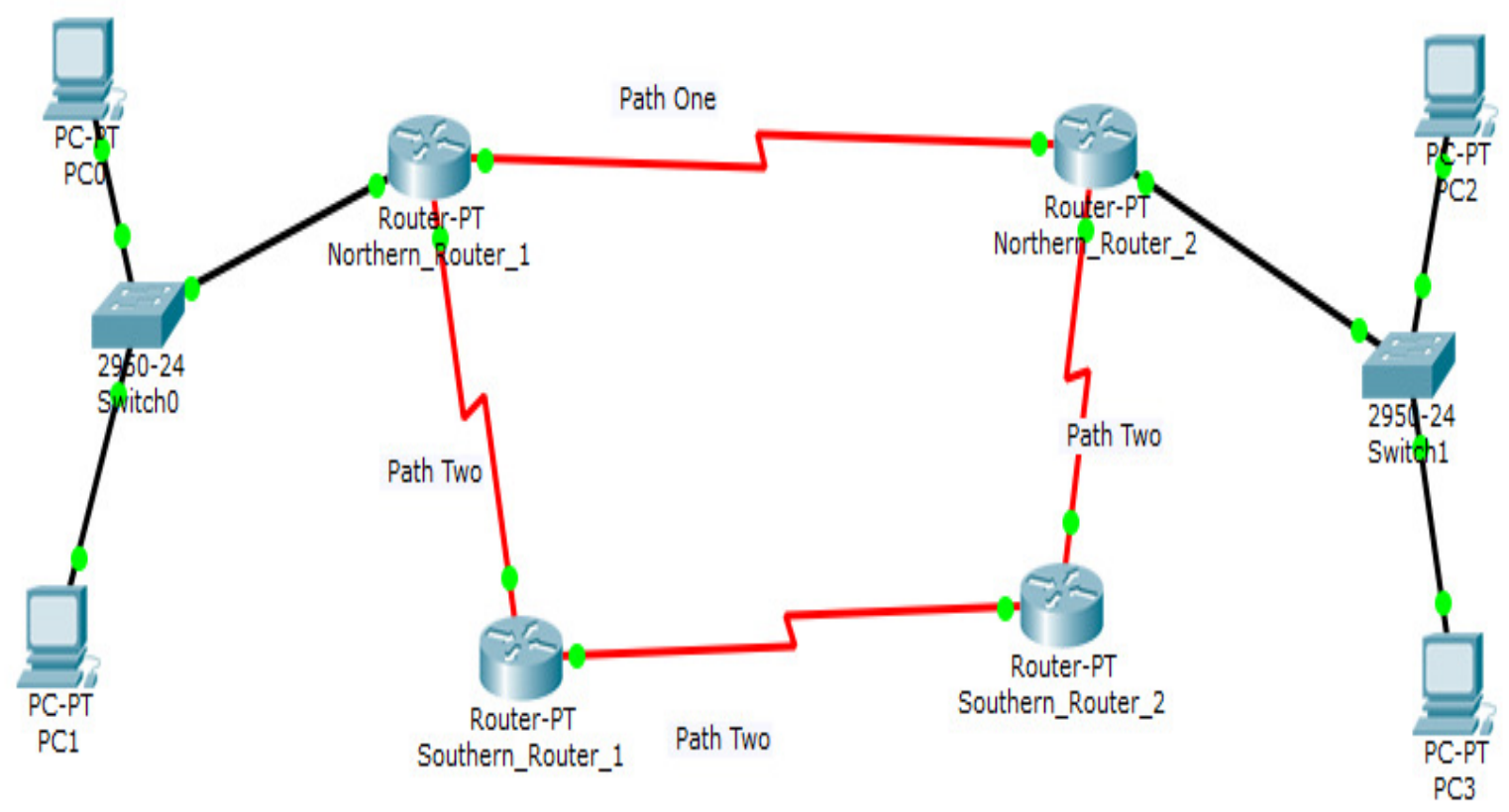

Figure 2: Source is Scepanovic \& Vukotic, 2013

The specific machine names and their respective configurations are provided below, the essence is to provide a broad overview of the simulated environment.

\section{Table 4: Address Configuration of Computers}

\begin{tabular}{|l|l|l|}
\hline No & Computers & IP Address \\
\hline 1 & PC0 & $10.0 .0 .1 / 8$ \\
\hline 2 & PC1 & $10.0 .0 .2 / 8$ \\
\hline 3 & PC2 & $20.0 .0 .1 / 8$ \\
\hline 4 & PC3 & $20.0 .0 .2 / 8$ \\
\hline
\end{tabular}


Table 5: Configuration of Routers on RIP and EIGRP Platforms

\begin{tabular}{|c|c|c|c|}
\hline No & Router & Configuration for RIP & Configuration for EIGRP \\
\hline 1 & Northern_Router_1 & $\begin{array}{l}\text { interface FastEthernet0/0 } \\
\text { ip address } 10.0 .0 .10255 .0 .0 .0 \\
\text { duplex auto } \\
\text { speed auto } \\
\text { interface Serial2/0 } \\
\text { bandwidth } 64000 \\
\text { ip address } 30.0 .0 .1255 .0 .0 .0 \\
\text { clock rate } 2000000 \\
\text { interface Serial3/0 } \\
\text { bandwidth } 1024000 \\
\text { ip address } 40.0 .0 .1255 .0 .0 .0 \\
\text { clock rate } 2000000 \\
\text { router rip } \\
\text { network } 10.0 .0 .0 \\
\text { network } 30.0 .0 .0 \\
\text { network } 40.0 .0 .0\end{array}$ & $\begin{array}{l}\text { interface FastEthernet0/0 } \\
\text { ip address } 10.0 .0 .10255 .0 .0 .0 \\
\text { duplex auto } \\
\text { speed auto } \\
\text { interface Serial2/0 } \\
\text { bandwidth } 64000 \\
\text { ip address } 30.0 .0 .1255 .0 .0 .0 \\
\text { clock rate } 2000000 \\
\text { interface Serial3/0 } \\
\text { bandwidth } 1024000 \\
\text { ip address } 40.0 .0 .1255 .0 .0 .0 \\
\text { clock rate } 2000000 \\
\text { router eigrp } 10 \\
\text { network } 10.0 .0 .0 \\
\text { network } 30.0 .0 .0 \\
\text { network } 40.0 .0 .0 \\
\text { auto-summary }\end{array}$ \\
\hline 2 & Northern_Router_2 & $\begin{array}{l}\text { interface FastEthernet0/0 } \\
\text { ip address } 20.0 .0 .10255 .0 .0 .0 \\
\text { duplex auto } \\
\text { speed auto } \\
\text { interface Serial2/0 } \\
\text { bandwidth } 64000 \\
\text { ip address } 30.0 .0 .2255 .0 .0 .0 \\
\text { interface Serial3/0 } \\
\text { bandwidth } 1024000 \\
\text { ip address } 60.0 .0 .2255 .0 .0 .0 \\
\text { clock rate } 2000000 \\
\text { router rip } \\
\text { network } 20.0 .0 .0 \\
\text { network } 30.0 .0 .0 \\
\text { network } 60.0 .0 .0\end{array}$ & $\begin{array}{l}\text { interface FastEthernet0/0 } \\
\text { ip address } 20.0 .0 .10255 .0 .0 .0 \\
\text { duplex auto } \\
\text { speed auto } \\
\text { interface Serial2/0 } \\
\text { bandwidth } 64000 \\
\text { ip address } 30.0 .0 .2255 .0 .0 .0 \\
\text { interface Serial3/0 } \\
\text { bandwidth } 1024000 \\
\text { ip address } 60.0 .0 .2255 .0 .0 .0 \\
\text { router eigrp } 10 \\
\text { network } 20.0 .0 .0 \\
\text { network } 30.0 .0 .0 \\
\text { network } 60.0 .0 .0 \\
\text { auto-summary }\end{array}$ \\
\hline 3 & Southern_Router_1 & $\begin{array}{l}\text { interface Serial2/0 } \\
\text { bandwidth } 1024000 \\
\text { ip address } 40.0 .0 .2255 \cdot 0.0 .0 \\
\text { interface Serial3/0 } \\
\text { bandwidth } 1024000 \\
\text { ip address } 50.0 .0 .1255 .0 .0 .0 \\
\text { clock rate } 2000000 \\
\text { router rip } \\
\text { network 40.0.0.0 } \\
\text { network 50.0.0.0 }\end{array}$ & $\begin{array}{l}\text { interface Serial2/0 } \\
\text { bandwidth } 1024000 \\
\text { ip address } 40.0 .0 .2255 .0 .0 .0 \\
\text { interface Serial3/0 } \\
\text { bandwidth } 1024000 \\
\text { ip address } 50.0 .0 .1255 .0 .0 .0 \\
\text { clock rate } 2000000 \\
\text { router eigrp } 10 \\
\text { network 50.0.0.0 } \\
\text { network 40.0.0.0 } \\
\text { auto-summary }\end{array}$ \\
\hline 4 & Southern_Router_2 & $\begin{array}{l}\text { interface Serial2/0 } \\
\text { bandwidth } 1024000 \\
\text { ip address 50.0.0.2 255.0.0.0 } \\
\text { interface Serial3/0 } \\
\text { bandwidth } 1024000 \\
\text { ip address } 60.0 .0 .1255 .0 .0 .0 \\
\text { router rip } \\
\text { network } 50.0 .0 .0 \\
\text { network } 60.0 .0 .0\end{array}$ & $\begin{array}{l}\text { interface Serial2/0 } \\
\text { bandwidth } 1024000 \\
\text { ip address } 50.0 .0 .2255 .0 .0 .0 \\
\text { interface Serial3/0 } \\
\text { bandwidth } 1024000 \\
\text { ip address } 60.0 .0 .1255 .0 .0 .0 \\
\text { clock rate } 2000000 \\
\text { router eigrp } 10 \\
\text { network } 50.0 .0 .0 \\
\text { network } 60.0 .0 .0 \\
\text { auto-summary }\end{array}$ \\
\hline
\end{tabular}




\section{RESULTS AND ANALYSIS}

The configurations shown in table 6 led to the generation of the routing tables depicted in tables 2 and 3 below; Applicable Codes for Displayed Routes

C - connected, S - static, I - IGRP, R - RIP, M - mobile, B - BGP, D - EIGRP, EX - EIGRP external, O - OSPF, IA - OSPF inter area, N1 - OSPF NSSA external type 1, N2 - OSPF NSSA external type 2, E1 - OSPF external type 1, E2 - OSPF external type 2, E - EGP, i - IS-IS, L1 - IS-IS level-1, L2 - IS-IS level-2, ia - IS-IS inter area, * - candidate default, U - peruser static route, o-ODR, $\mathrm{P}$ - periodic downloaded static route

Table 6: Routing Table for RIP Configuration

\begin{tabular}{|c|c|c|}
\hline No & Router & RIP Routing Table \\
\hline 1 & Northern_Router_1 & $\begin{array}{l}\text { C } 10.0 .0 .0 / 8 \text { is directly connected, FastEthernet0/0 } \\
\text { R } 20.0 .0 .0 / 8 \text { [120/1] via } 30.0 .0 .2,00: 00: 25 \text {, Serial2/0 } \\
\text { C } 30.0 .0 .0 / 8 \text { is directly connected, Serial2/0 } \\
\text { C } 40.0 .0 .0 / 8 \text { is directly connected, Serial3/0 } \\
\text { R } 50.0 .0 .0 / 8 \text { [120/1] via } 40.0 .0 .2,00: 00: 03 \text {, Serial3/0 } \\
\text { R } 60.0 .0 .0 / 8[120 / 1] \text { via } 30.0 .0 .2,00: 00: 25 \text {, Serial2/0 }\end{array}$ \\
\hline 2 & Northern_Router_2 & $\begin{array}{l}\mathrm{R} 10.0 .0 .0 / 8 \text { [120/1] via 30.0.0.1, 00:00:26, Serial2/0 } \\
\text { C } 20.0 .0 .0 / 8 \text { is directly connected, FastEthernet0/0 } \\
\text { C } 30.0 .0 .0 / 8 \text { is directly connected, Serial2/0 } \\
\mathrm{R} 40.0 .0 .0 / 8[120 / 1] \text { via } 30.0 .0 .1,00: 00: 26 \text {, Serial2/0 } \\
\mathrm{R} 50.0 .0 .0 / 8[120 / 1] \text { via } 60.0 .0 .1,00: 00: 09 \text {, Serial3/0 } \\
\text { C } 60.0 .0 .0 / 8 \text { is directly connected, Serial3/0 }\end{array}$ \\
\hline 3 & Southern_Router_1 & $\begin{array}{l}\text { R 10.0.0.0/8 [120/1] via 40.0.0.1, 00:00:00, Serial2/0 } \\
\text { R 20.0.0.0/8 [120/2] via 50.0.0.2, 00:00:12, Serial3/0 } \\
\text { [120/2] via 40.0.0.1, 00:00:00, Serial2/0 } \\
\text { R } 30.0 .0 .0 / 8[120 / 1] \text { via } 40.0 .0 .1,00: 00: 00 \text {, Serial2/0 } \\
\text { C } 40.0 .0 .0 / 8 \text { is directly connected, Serial2/0 } \\
\text { C 50.0.0.0/8 is directly connected, Serial3/0 } \\
\text { R } 60.0 .0 .0 / 8[120 / 1] \text { via } 50.0 .0 .2,00: 00: 12 \text {, Serial3/0 }\end{array}$ \\
\hline 4 & Southern_Router_2 & $\begin{array}{l}\mathrm{R} 10.0 .0 .0 / 8[120 / 2] \text { via } 50.0 .0 .1,00: 00: 27 \text {, Serial2/0 } \\
\mathrm{R} 20.0 .0 .0 / 8[120 / 1] \text { via } 60.0 .0 .2,00: 00: 16 \text {, Serial3/0 } \\
\mathrm{R} 30.0 .0 .0 / 8[120 / 1] \text { via } 60.0 .0 .2,00: 00: 16 \text {, Serial3/0 } \\
\mathrm{R} 40.0 .0 .0 / 8[120 / 1] \text { via } 50.0 .0 .1,00: 00: 27 \text {, Serial2/0 } \\
\text { C } 50.0 .0 .0 / 8 \text { is directly connected, Serial2/0 } \\
\text { C } 60.0 .0 .0 / 8 \text { is directly connected, Serial3/0 }\end{array}$ \\
\hline
\end{tabular}

Table 7: Routing Table for EIGRP Configuration

\begin{tabular}{|c|c|c|}
\hline No & Router & EIGRP Routing Table \\
\hline 1 & Northern_Router_1 & $\begin{array}{l}\text { C } 10.0 .0 .0 / 8 \text { is directly connected, FastEtherneto/0 } \\
\text { D } 20.0 .0 .0 / 8 \text { [90/554496] via } 30.0 .0 .2,00: 07: 00 \text {, Serial2/0 } \\
\text { C } 30.0 .0 .0 / 8 \text { is directly connected, Serial2/0 } \\
\text { C } 40.0 .0 .0 / 8 \text { is directly connected, Serial3/0 } \\
\text { D } 50.0 .0 .0 / 8 \text { [90/1026304] via } 40.0 .0 .2,00: 07: 02, \text { Serial3/0 } \\
\text { D } 60.0 .0 .0 / 8[90 / 1063936] \text { via } 30.0 .0 .2,00: 07: 00 \text {, Serial } 2 / 0\end{array}$ \\
\hline 2 & Northern_Router_2 & $\begin{array}{l}\text { D } 10.0 .0 .0 / 8[90 / 554496] \text { via } 30.0 .0 .1,00: 07: 40 \text {, Serial2/0 } \\
\text { C } 20.0 .0 .0 / 8 \text { is directly connected, FastEthernet0/0 } \\
\text { C } 30.0 .0 .0 / 8 \text { is directly connected, Serial2/0 } \\
\text { D 40.0.0.0/8 [90/1063936] via 30.0.0.1, 00:07:40, Serial2/0 } \\
\text { D 50.0.0.0/8 [90/1026304] via 60.0.0.1, 00:07:42, Serial3/0 } \\
\text { C 60.0.0.0/8 is directly connected, Serial3/0 }\end{array}$ \\
\hline 3 & Southern_Router_1 & $\begin{array}{l}\text { D } 10.0 .0 .0 / 8 \text { [90/540160] via 40.0.0.1, 00:06:23, Serial2/0 } \\
\text { D 20.0.0.0/8 [90/1052160] via } 50.0 .0 .2,00: 06: 23 \text {, Serial3/0 } \\
\text { D } 30.0 .0 .0 / 8 \text { [90/1063936] via } 40.0 .0 .1,00: 06: 23 \text {, Serial2/0 } \\
\text { C } 40.0 .0 .0 / 8 \text { is directly connected, Serial2/0 } \\
\text { C } 50.0 .0 .0 / 8 \text { is directly connected, Serial3/0 } \\
\text { D 60.0.0.0/8 [90/1026304] via 50.0.0.2, 00:06:23, Serial3/0 }\end{array}$ \\
\hline 4 & Southern_Router_2 & $\begin{array}{l}\text { D } 10.0 .0 .0 / 8[90 / 1052160] \text { via } 50.0 .0 .1,00: 05: 33 \text {, Serial2/0 } \\
\text { D } 20.0 .0 .0 / 8[90 / 540160] \text { via } 60.0 .0 .2,00: 05: 33 \text {, Serial3/0 } \\
\text { D } 30.0 .0 .0 / 8[90 / 1063936] \text { via } 60.0 .0 .2,00: 05: 31, \text { Serial3/0 } \\
\text { D 40.0.0.0/8 [90/1026304] via } 50.0 .0 .1,00: 05: 33 \text {, Serial2/0 } \\
\text { C } 50.0 .0 .0 / 8 \text { is directly connected, Serial2/0 } \\
\text { C } 60.0 .0 .0 / 8 \text { is directly connected, Serial3/0 }\end{array}$ \\
\hline
\end{tabular}


The results obtained from the connectivity tests are as detailed below;

\section{RIP Results via Path One}

\section{C:l>tracert 10.0.0.1}

Tracing route to 10.0 .0 .1 over a maximum of 30 hops:

$12 \mathrm{~ms} 0 \mathrm{~ms} 0 \mathrm{~ms} \quad 20.0 .0 .10$

$21 \mathrm{~ms} \quad 0 \mathrm{~ms} \quad 0 \mathrm{~ms} \quad 30.0 .0 .1$

$\begin{array}{llll}1 \mathrm{~ms} & 2 \mathrm{~ms} \quad 1 \mathrm{~ms} \quad 10.0 .0 .1\end{array}$

Trace complete.

\section{C:l>ping 10.0.0.1}

Pinging 10.0.0.1 with 32 bytes of data:

Reply from 10.0.0.1: bytes $=32$ time $=1 \mathrm{~ms} T T L=126$

Reply from 10.0.0.1: bytes $=32$ time $=1 \mathrm{~ms} T T L=126$

Reply from 10.0.0.1: bytes $=32$ time $=1 \mathrm{~ms}$ TTL $=126$

Reply from 10.0.0.1: bytes $=32$ time $=1 \mathrm{~ms} T \mathrm{TL}=126$

Ping statistics for 10.0.0.1:

Packets: Sent $=4$, Received $=4$, Lost $=0$ (0\% loss), Approximate round trip times in milli-seconds:

Minimum $=1 \mathrm{~ms}$, Maximum $=1 \mathrm{~ms}$, Average $=1 \mathrm{~ms}$

C:l $>$ tracert 10.0.0.1

Tracing route to 10.0.0.1 over a maximum of 30 hops:

$10 \mathrm{~ms} \quad 1 \mathrm{~ms} \quad 1 \mathrm{~ms} \quad 20.0 .0 .10$

$20 \mathrm{~ms} \quad 1 \mathrm{~ms} \quad 1 \mathrm{~ms} \quad 60.0 .0 .1$

$\begin{array}{lllll}3 & 3 \mathrm{~ms} & 1 \mathrm{~ms} & 2 \mathrm{~ms} \quad 50.0 .0 .1\end{array}$

$42 \mathrm{~ms} \quad 1 \mathrm{~ms} \quad 1 \mathrm{~ms} \quad 40.0 .0 .1$

$511 \mathrm{~ms} \quad 11 \mathrm{~ms} \quad 11 \mathrm{~ms} \quad 10.0 .0 .1$

Trace complete.

C:l>ping 10.0.0.1

Pinging 10.0.0.1 with 32 bytes of data:

Reply from 10.0.0.1: bytes $=32$ time $=3 \mathrm{~ms} T T L=124$

Reply from 10.0.0.1: bytes $=32$ time $=11 \mathrm{~ms}$ TTL $=124$

Reply from 10.0.0.1: bytes $=32$ time $=11 \mathrm{~ms} T T L=124$

Reply from 10.0.0.1: bytes $=32$ time $=11 \mathrm{~ms}$ TTL $=124$

Ping statistics for 10.0.0.1:

Packets: Sent $=4$, Received $=4$, Lost $=0$ ( $0 \%$ loss), Approximate round trip times in milli-seconds:

Minimum $=3 \mathrm{~ms}$, Maximum $=11 \mathrm{~ms}$, Average $=9 \mathrm{~ms}$

\section{RIP Results via Path Two}

\section{C:l>tracert 10.0.0.1}

Tracing route to 10.0 .0 .1 over a maximum of 30 hops:

$\begin{array}{lllll}1 & 0 \mathrm{~ms} & 1 \mathrm{~ms} & 1 \mathrm{~ms} & 20.0 .0 .10 \\ 2 & 0 \mathrm{~ms} & 2 \mathrm{~ms} & 0 \mathrm{~ms} & 30.0 .0 .1 \\ 3 & 1 \mathrm{~ms} & 0 \mathrm{~ms} & 0 \mathrm{~ms} & 10.0 .0 .1\end{array}$

Trace complete.

C:l>ping 10.0.0.1

Pinging 10.0.0.1 with 32 bytes of data:

Reply from 10.0.0.1: bytes $=32$ time $=1 \mathrm{~ms} T T L=126$ 
Reply from 10.0.0.1: bytes $=32$ time $=1 \mathrm{~ms} T T L=126$

Reply from 10.0.0.1: bytes $=32$ time $=1 \mathrm{~ms} T T L=126$

Reply from 10.0.0.1: bytes $=32$ time $=1 \mathrm{~ms} T T L=126$

Ping statistics for 10.0.0.1:

Packets: Sent $=4$, Received $=4$, Lost $=0$ ( $0 \%$ loss),

Approximate round trip times in milli-seconds:

Minimum $=1 \mathrm{~ms}$, Maximum $=1 \mathrm{~ms}$, Average $=1 \mathrm{~ms}$

\section{EIGRP Results via Path One}

C:I>ping 10.0.0.1

Pinging 10.0.0.1 with 32 bytes of data:

Request timed out.

Reply from 10.0.0.1: bytes $=32$ time $=2 \mathrm{~ms} T \mathrm{TTL}=126$

Reply from 10.0.0.1: bytes $=32$ time $=2 \mathrm{~ms} T T L=126$

Reply from 10.0.0.1: bytes $=32$ time $=10 \mathrm{~ms} T T L=126$

Ping statistics for 10.0.0.1:

Packets: Sent $=4$, Received $=3$, Lost $=1$ (25\% loss), Approximate round trip times in milli-seconds:

Minimum $=2 \mathrm{~ms}$, Maximum $=10 \mathrm{~ms}$, Average $=4 \mathrm{~ms}$

C:I>tracert 10.0.0.1

Tracing route to 10.0 .0 .1 over a maximum of 30 hops:

$11 \mathrm{~ms} \quad 0 \mathrm{~ms} \quad 0 \mathrm{~ms} \quad 20.0 .0 .10$

$\begin{array}{lllll}2 & 1 \mathrm{~ms} & 0 \mathrm{~ms} & 2 \mathrm{~ms} & 30.0 .0 .1\end{array}$

$\begin{array}{lllll}3 & 0 \mathrm{~ms} & 0 \mathrm{~ms} & 0 \mathrm{~ms} & 10.0 .0 .1\end{array}$

Trace complete.

\section{EIGRP Results via Path Two}

\section{C:I>tracert 10.0.0.1}

Tracing route to 10.0 .0 .1 over a maximum of 30 hops:

$\begin{array}{lllll}1 & 0 \mathrm{~ms} & 0 \mathrm{~ms} & 0 \mathrm{~ms} & 20.0 .0 .10 \\ 2 & 1 \mathrm{~ms} & 2 \mathrm{~ms} & 0 \mathrm{~ms} & 60.0 .0 .1 \\ 3 & 0 \mathrm{~ms} & 1 \mathrm{~ms} & 1 \mathrm{~ms} & 50.0 .0 .1 \\ 4 & 3 \mathrm{~ms} & 10 \mathrm{~ms} & 0 \mathrm{~ms} & 40.0 .0 .1 \\ 5 & 11 \mathrm{~ms} & 12 \mathrm{~ms} & 11 \mathrm{~ms} & 10.0 .0 .1\end{array}$

Trace complete.

C:I>ping 10.0.0.1

Pinging 10.0.0.1 with 32 bytes of data:

Reply from 10.0.0.1: bytes $=32$ time $=4 \mathrm{~ms} T \mathrm{TT}=124$

Reply from 10.0.0.1: bytes $=32$ time $=11 \mathrm{~ms} T \mathrm{TT}=124$

Reply from 10.0.0.1: bytes $=32$ time $=11 \mathrm{~ms} T \mathrm{TL}=124$

Reply from 10.0.0.1: bytes $=32$ time $=11 \mathrm{~ms} T T L=124$

Ping statistics for 10.0.0.1:

Packets: Sent $=4$, Received $=4$, Lost $=0$ (0\% loss),

Approximate round trip times in milli-seconds:

Minimum $=4 \mathrm{~ms}$, Maximum $=11 \mathrm{~ms}$, Average $=9 \mathrm{~ms}$

C:I tracert 10.0.0.1

Tracing route to 10.0 .0 .1 over a maximum of 30 hops:

$10 \mathrm{~ms} \quad 0 \mathrm{~ms} \quad 1 \mathrm{~ms} \quad 20.0 .0 .10$ 
$\begin{array}{lllll}2 & 1 \mathrm{~ms} & 2 \mathrm{~ms} & 0 \mathrm{~ms} & 30.0 .0 .1\end{array}$

$30 \mathrm{~ms} \quad 1 \mathrm{~ms} \quad 1 \mathrm{~ms} \quad 10.0 .0 .1$

Trace complete.

C:l>ping 10.0.0.1

Pinging 10.0.0.1 with 32 bytes of data:

Reply from 10.0.0.1: bytes $=32$ time $=1 \mathrm{~ms} T T L=126$

Reply from 10.0.0.1: bytes $=32$ time $=1 \mathrm{~ms} T T L=126$

Reply from 10.0.0.1: bytes $=32$ time $=1 \mathrm{~ms} T T L=126$

Reply from 10.0.0.1: bytes $=32$ time $=2 \mathrm{~ms} T \mathrm{TL}=126$

Ping statistics for 10.0.0.1:

Packets: Sent $=4$, Received $=4$, Lost $=0$ (0\% loss), Approximate round trip times in milli-seconds:

Minimum $=1 \mathrm{~ms}$, Maximum $=2 \mathrm{~ms}$, Average $=1 \mathrm{~ms}$

Table 8: Empirical Comparison Simulation Results

\begin{tabular}{|l|c|c|}
\hline \multicolumn{1}{|c|}{ Metric } & $\begin{array}{c}\text { RIP Platform Values } \\
\text { (milli-seconds) }\end{array}$ & $\begin{array}{c}\text { EIGRP Platform Values } \\
\text { (milli-seconds) }\end{array}$ \\
\hline Path One Time to Live (Average) & 4 & 4 \\
\hline Path One Round Trip (Average) & 1 & 4 \\
\hline Path Two Time to Live (Average) & 11 & 11.3 \\
\hline Path Two Round Trip (Average) & 4 & 9 \\
\hline
\end{tabular}

Table 8 shows a summarized comparison of the test output, the metrics for comparison are the average time to live and average round trip from the "tracert" and "ping" results. Evidently, the average time to live is consistent by default for both routing protocols however, the round trip produces significantly varying results. RIP tends to produce quicker round trips averaging 4 milli-seconds whereas EIGRP produces 9 milli-seconds on a bandwidth of 1024000Kbps. On the bandwidth of $64 \mathrm{Kbps}$, RIP tends to produce quicker round trips averaging 1 milli-seconds whereas EIGRP produces 4 milli-seconds. The results obtained imply a speed of over $100 \%$ faster in transmission over an RIP network as against an EIGRP network.

Scepanovic et al. (2013) posited that "in most cases (when network is configured as bus, point-to-point, ring or hierarchy topology) message sending time is equal for the RIP and for the EIGRP protocols and does not depend on the bandwidth of links or on the number of sent packages. But in cases when because of the greater bandwidth of links, EIGRP chooses faster but longer path, message sending time through those paths is much fewer than through paths which RIP chose. Based on all results which were obtained, it was concluded that in most cases EIGRP is preferable protocol, especially when great amount of data has to be sent through the network".

The findings in this research is however not absolutely consistent with that of Deng et al (2014) as cited under "Related Research" and Scepanovic et al (2013) above, this is mainly because emphasis in this experiment is on round trip and time to live and not convergence time. The results clearly depicts a different picture where RIP is experienced as having a faster round trip compared to EIGRP under the topology shown in figure 1.

\section{CONCLUSION}

This paper set out to empirically compare the two routing protocols Routing Information Protocol (RIP) and Enhanced Interior Gateway Routing Protocol (EIGRP). Having developed a simulated environment with a network setup to test and compare overall round trip times and time to live values experienced on a single topology and different bandwidths, the results of the experiment showed that RIP provides faster transmission and response times as compared to EIGRP implementation under the simulated environment in the event of all conditions are equal. Compared to earlier research work done predominantly on inherent metrics of the routing protocols, this research output tells a relatively different story from that experienced by simulations done with inherent features as the focus. The researcher would recommend that this research is done on multiple topologies for further validity and reliability of findings. 


\section{DIRECTION FOR FUTURE WORK}

Given the outcome of this research, it is evident that inherent metrics of routing protocols do not necessarily translate into overall throughput and performance. A necessary future work would be to replicate the research in different topologies and also an attempt to compare other routing protocols from a throughput and performance perspective.

\section{References}

1. Almquist P. (1994), Towards Requirements for IP Routers, RFC 1716

2. Atkinson R. and Fanto M.(2007), RFC 4822, RIPv2 Cryptographic Authentication, The Internet Society

3. Baker F. (1995), Requirements for IP Version 4 Routers, RFC 1812

4. Balchunas, Aaron. "Routing Information Protocol (RIP v1.03)" (PDF). http://www.routeralley.com. Retrieved 25 April 2014.

5. Bellman, Richard (1958). "On a routing problem". Quarterly of Applied Mathematics. 16: 87-90. MR 0102435.

6. Comer D.E. (2000). Internetworking with TCP/IP - Principles, Protocols and Architecture (4th ed.). Prentice Hall. p. 226. ISBN 0-13-018380-6.

7. Deng J.,Wu S. and Sun K. (2014), Comparison of RIP, OSPF and EIGRP Routing Protocols based on OPNET, ENSC 427: COMMUNICATION NETWORKS SPRING 2014, FINAL PROJECT

8. Doyle J. \& Carroll J. (2005). CCIE Professional Development: Routing TCP/IP Volume I, Second Edition. ciscopress.com. p. 169. ISBN 9781587052026.

9. Fuller V. and Li T. (August 2006). Classless Inter-domain Routing (CIDR): The Internet Address Assignment and Aggregation Plan. doi:10.17487/RFC4632

10. Lammle, Todd (2007), CCNA Cisco Certified Network Associate Study Guide (Sixth ed.), Indianapolis, Indiana: Wiley Publishing, ISBN 978-0-470-11008-9.

11. Laung-Terng Wang, Yao-Wen Chang, Kwang-Ting (Tim) Cheng (2009). Electronic Design Automation: Synthesis, Verification, and Test. Morgan Kaufmann. p. 204. ISBN 0080922007

12. Malkin, Gary Scott (2000). RIP: An Intra-Domain Routing Protocol. Addison-Wesley Longman. ISBN 0-20143320-6.

13. Mogul J.(1984) Broadcasting Internet Datagrams In The Presence Of Subnets, RFC 922,

14. Moy J.T. (1998) OSPF: Anatomy of an Internet Routing Protocol 1st Edition, ISBN-13: 978- 0201634723, ISBN10: 0201634724

15. Pepelnjak I. (2000), EIGRP Network Design Solutions: The Definitive Resource for EIGRP Design, Deployment, and Operation.

16. Postel J.(1981), Internet Protocol, RFC 791

17. Scepanovic S. and Vukotic I. (2013), RIP VS. EIGRP, MATHEMATICA MONTISNIGRI Vol XXVIII pp. 109-123

18. Seeger J. and Khanna A. (1986), Reducing Routing Overhead in a Growing DDN, MILCOMM '86, IEEE

19. Winsberg E.(2003), Methodology for a Virtual World, Philosophy of Science, Vol. 70, No. 1 pp. 105-125 


\section{ABOUT AUTHORS}

\section{Dr. Paul Danquah}

Dr. Paul Asante Danquah is an IT professional and a Senior Lecturer at the Heritage Christian College in Accra, Ghana. He holds a BSc HONS in Computing, MSc in Information Security and a PhD in IT (Specialized in Cybercrime) from the University of Greenwich UK, Anglia Ruskin University UK and Open University Malaysia respectively. He has various industry certifications, some of which are Certified Ethical Hacker (CEH), Data Center Infrastructure Expert (DCIE), Cisco Certified Network Professional (CCNP) and Microsoft Certified Systems Engineer (MCSE). Dr. Paul Danquah has worked in various capacities over the last 20 years, these range from Programmer, Network Engineer, IT Manager and Technical Director of various organizations.

\section{Mr. Jojo Lartey}

Mr. Jojo Desmond Lartey is an Assistant Lecturer at the department of Information Technology, Heritage Christian University College, Ghana. His main areas of interest are computational intelligence and dynamical systems. He has BSc. Mathematics from Kwame Nkrumah University of Science and Technology Ghana, MSc. in Industrial Mathematical Modelling from Loughborough University England, and PGCert. in Advanced Computer Systems Development from University of the West of Scotland, Scotland. He is currently investigating traffic control at UNISA as a PhD candidate and he is a member of Society for Industrial and Applied Mathematics (SIAM).

\section{Mr. John Kani}

Mr. John Kani is an Assistant Lecturer with Heritage Christian College. Mr. Kani is currently a PhD candidate who holds MSc in Information Systems and Bachelor in Management Studies from University of Cape Coast. 